\title{
A questão da terminalidade
}

\section{The issue of terminally ill patients}

\author{
Mauro Hilkner', Regiane Rossi Hilkner²
}

"Tudo tem seu tempo, o momento oportuno para todo propósito debaixo do sol. Tempo de nascer, tempo de morrer". Eclesiastes (Ec. 3; 1 e 2).

Hilkner M, Hilkner RR. A questão da terminalidade. Saúde, Ética \& Justiça. 2012;17(2):75-81.

RESUMO: Os autores abordam a situação dos pacientes irreversivelmente enfermos, comumente internados em leitos de Unidades de Terapia Intensiva, e sua complexa relação com médicos, familiares e a sociedade. Discutem a terminalidade da vida, que pode ensejar conflitos de interesse, profissionais, éticos e de crenças, além de questões relativas à alocação de recursos na área da saúde.

DESCRITORES: Estado terminal; Unidade de terapia intensiva; Ética médica; Bioética; Cuidados paliativos.

\footnotetext{
1. Médico Intensivista, Doutor em Emergências Clínicas pela FMUSP, Médico Assistente da UTI da Neurologia do HCFMUSP e Coordenador da UTI do Hospital Samaritano de Campinas.

2. Pedagoga, Mestre em Psicologia pela UNICAMP e Doutora em Antropologia pela UNICAMP. Coordenadora da graduação em Educação e da pós-graduação em Psicologia e Psicopedagogia do UNISAL - Americana, São Paulo. Endereço para correspondência: Dr. Mauro Hilkner. Rua Serra do Japi, 234. Jd. Paranapanema, Campinas, SP. CEP: 13.100-269 E-mail: mhilkner@uol.com.br
} 
$\mathrm{P}$ ara todo ser vivo existe um fim desse ciclo biológico, muitas vezes determinado somente pela senilidade. Comumente, também, doenças de variável gravidade são determinantes dessa terminalidade da vida, mais acentuadamente quando incuráveis. Estados clínicos agudos, infecciosos ou traumáticos também concorrem para esse estágio terminal, particularmente quando associados às insuficiências ou disfunções de múltiplos órgãos.

Os últimos vinte anos na área médica foram de progressos acentuados e combinados com a evolução da bioengenharia, da ciência da computação, da nanotecnologia e dos progressos da indústria química farmacêutica. Isso se comprova quando observamos, dentre outras coisas, a confiabilidade e a precisão dos ventiladores mecânicos, das máquinas de hemodiálise, dos monitores em geral, do amplo espectro dos novos antibióticos e quimioterápicos e a facilidade para a realização precoce e repetida de diagnóstico por tomografia, ressonância magnética, ultrassonografia, ecocardiograma, cateterismo cardíaco e medicina nuclear ${ }^{1}$.

Associado a isso, há de se considerar o volume de trabalhos apresentados na literatura médica mundial que, hoje, são ampla e facilmente, tanto divulgados, quanto acessados pela internet.

A combinação de todos esses fatores com protocolos de conduta bem estabelecidos e profissionais melhor treinados tem interferido positivamente sobre doentes e doenças até há pouco tempo muito difíceis de serem tratadas. Mas, também, tem produzido a manutenção de pacientes, que sabidamente não têm prognóstico de melhora clínica ou mesmo de sobrevida sem todo esse aporte nas Unidades de Terapia Intensiva, vivos por mais tempo, ou por tempo indeterminado. Esse crescimento da capacidade de intervenção médica e a possibilidade de adiar indefinidamente a morte precisam ser discutidos. Obviamente, aqui cabe a tese clássica de que o médico não deve abandonar nunca seu paciente e deve continuar tentando tudo enquanto houver o mínimo sinal de vida. Dessa forma, nenhuma intervenção poderia ser considerada fútil ou inútil e isso define a distanásia, ou seja, uma obstinação diagnóstica e terapêutica².

Existe unanimidade em se admitir que essa situação é um problema real que precisa ser solucionado. Independentemente do nome que se dê a esse quadro, toda ação, procedimento ou intervenção médica que não atinge o objetivo de beneficiar a pessoa na terminalidade biológica e que somente prolonga de maneira inútil o processo de morrer, distanciando a morte, merece discussão². As discussões sobre a preservação da vida têm, nitidamente, maior volume e alcance que as discussões sobre a terminalidade da mesma. A sociedade e seus legisladores discutem a obrigatoriedade do uso de capacetes, de cinto de segurança, do assento infantil nos carros, dos limites de velocidade, a proibição das drogas e seus derivados visando sempre à proteção e à preservação humana.

Nesse contexto, a distanásia tem recebido muito menos atenção que outros temas controversos que fazem parte da internação hospitalar de um paciente gravemente enfermo e sem prognóstico de vida. Globalmente se discute mais a eutanásia ${ }^{3,4}$ - proibida em nosso país - e, muitas vezes, confundida com a distanásia, que se refere somente à ineficácia que essa obstinação terapêutica onerosa possui, mais comumente em UTIs, e que nada acrescenta ao paciente nesse estágio final de sua vida.

É importante a distinção entre atos médicos inúteis ou infrutíferos de omissão quando do fim da vida ${ }^{5}$. Esses atos não prolongam a vida propriamente dita, mas, sim, o processo de morrer ${ }^{2}$. Isso nos leva a um grande desafio: discutir a distanásia eticamente.

O primeiro objetivo da terapia intensiva poderia ser definir quais pacientes devem ser tratados. Com as técnicas de suporte de vida, até o termo "vivo" não constitui mais um conceito simples. Antes que interviéssemos para criar esse estado inédito de morrer, artificialmente prolongado e sustentado nas UTIs, o período de morrer era misericordiosamente curto ${ }^{6}$.

Esse quadro leva a pareceres diversos e análises calorosas e, dentre elas, há inevitavelmente a questão dos custos envolvidos e da alocação de recursos na área da saúde. Quando o gasto referente a esse conjunto de medidas obstinadas estiver focado em um hospital privado e por conta de familiares que necessitam se desfazer de bens acumulados durante toda uma vida, na prática, há uma diferença em relação à situação encontrada nos hospitais públicos, onde esses mesmos esforços infrutíferos podem ser mantidos a todo custo sem um questionamento financeiro direto.

O Sistema Único de Saúde (SUS), já deficitário e historicamente com tantos problemas, obviamente também sente esse percentual de despesa que compromete seus beneficiários e onera até aposentados em nosso país ${ }^{7}$.

Assim, a considerável quantia de dinheiro utilizada em quadros clínicos sem a obtenção de um real benefício poderia ser destinada a situações que gerariam saúde e atingiriam maior número de 
pessoas. Consequentemente, as questões acerca do tratamento fútil são importantes, não somente para os profissionais da saúde e pacientes, mas também para a sociedade como um todo. Está em questão o verdadeiro significado e o lugar da medicina na sociedade e a extensão da autoridade que essa sociedade outorga aos profissionais da saúde ${ }^{8}$.

Os planos de saúde tentam, seja por auditoria ou por restrições outras, dificultar a continuidade desses gastos, mas também é verdade que, sob as justificativas apresentadas pelo médico prescritor, habitualmente liberam os procedimentos e arcam com os gastos, o que aumenta a sinistralidade e, consequentemente, o rateio entre os usuários, o que torna os convênios médicos mais caros e alguns até proibitivos. Em outras palavras, a manutenção da terminalidade clínica ou o prolongamento artificial da vida repercute em toda a sociedade.

Os latinos, de uma forma geral, têm uma emotividade que contrasta com o mesmo sentimento dos europeus e orientais, e cada nação e cultura tem uma forma diferente, um olhar distinto para o mesmo problema ${ }^{9}$.

Além de todos os aspectos da cultura na qual crescemos, quando há um paciente terminal no hospital ou na UTI, frequentemente observamos importante discórdia entre os seus próprios familiares que, mesmo tendo visões distintas - ou não - da mesma situação, muitas vezes carregam medos, culpas e conflitos não resolvidos com o próprio paciente em questão e solicitam que tudo seja feito em seu favor como uma forma compensatória de seus próprios problemas anteriores com o doente. Dependência emocional, questões financeiras, como heranças, benefícios que cessarão com a morte e testamentos fazem familiares, nesse momento difícil, transitarem da racionalidade à emotividade com muita frequência e sem consenso.

Mas a abordagem da terminalidade não é, definitivamente, um problema que atinge somente custos e familiares. Entre os médicos, também não há consenso e falta a mesma racionalidade. Um professor, em palestra sobre o doente cirúrgico terminal, contou que, sentindo certa dificuldade em definir exatamente esse paciente, solicitou a colaboração de três oncologistas. Dos três, ouviu a mesma resposta: esse doente não existe. Esse episódio ouvido num anfiteatro por centenas de médicos ilustra bem o grau de dificuldade que envolve o fim da vida, mesmo entre profissionais da saúde.

Nas UTIs, o problema é sempre presente e discutido com maior frequência que nos demais setores hospitalares. Porém, nessas unidades, há muitos plantonistas, mas poucos intensivistas de formação e titulação e uma heterogeneidade natural além de conflitos de interesse. Nem sempre um profissional de plantão tem envolvimento com toda a evolução da doença de um paciente ali internado e nem sempre concorda com os rumos do tratamento decididos, por vezes conjuntamente com os familiares. Acossados pelo temor de qualquer acusação por não terem feito tudo pelo paciente em questão, não só ainda investem muito nesses casos, como deixam isso registrado nas evoluções médicas. Mas, será possível afirmar que um procedimento seja realmente "em favor" de um paciente quando, sabidamente, sua morte é esperada? Não se estaria somente diante da prática defensiva da medicina, na qual o médico age prioritariamente evitando processos judiciais ${ }^{10}$ ?

A questão é que se espera do médico que evite uma morte, e muitos médicos admitem isso. Também é certo que não podemos desconsiderar a possibilidade de erro de diagnóstico de "paciente terminal" e, além disso, por muitas vezes, os médicos temem seus próprios Conselhos de classe que afiguram-se como inquisidores, dificultando ainda mais a situação perante esse tipo de paciente em leitos da Terapia Intensiva ${ }^{11}$.

Por outro lado, não infrequentemente, médicos de plantão nas UTIs obedecem a decisões previamente tomadas e discutidas com os familiares. Mas também há casos de profissionais que administram mal o fato de não poderem fazer tudo naquela hora pela manutenção da vida, mesmo tratando-se de doença ou quadro clínico irreversível, intratável ou sem prognóstico. Esses intensivistas não receberam formação médica e treinamento nesse sentido específico e também têm suas convicções, dúvidas e inseguranças abaladas nessas situações e agravadas justamente por cumprirem o que já foi acordado com os familiares e que, eventualmente, fere as suas crenças.

Por Lei Natural, a obrigação de conservar a vida alheia prevalece sobre a obrigação de respeitar a liberdade e a consciência do próximo ${ }^{2,3}$, mas a conservação em questão é totalmente diferente da manutenção sem objetivo, sem perspectiva de cura, de melhora ou mesmo de atenuação de sofrimento. Nos casos de irreversibilidade, não deve deixar de haver assistência médica. Deve ocorrer apenas um exercício de prudência na escolha dos meios terapêuticos apropriados ${ }^{10}$.

$\mathrm{Na}$ visão dos autores, vivemos numa cultura médica paternalista. Temos a impressão que isso ocorre mais acentuadamente entre os idosos e os médicos. Com muita freqüência, ouvimos 
"Doutor, o senhor decide" e "estou em suas mãos". Frases como "primeiro Deus e depois o médico" fazem parte da nossa sociedade e evolução. Essa discutível relação torna ainda mais conflituosa a abordagem dos pacientes que, clinicamente, estejam na terminalidade da vida.

O modelo oferecido é aquele da relação entre um pai e seu filho, o paternalismo benevolente que continua permeando boa parte da prática médica contemporânea. Numerosas supostas justificativas embasam a prática do paternalismo médico. A mais alegada e provavelmente a mais importante é que a ética médica naturalmente a exigiria. $\mathrm{O}$ próprio juramento de Hipócrates é citado: "Aplicarei os regimes para o bem dos doentes, segundo o meu saber e a minha razão, nunca para prejudicar ou fazer mal a quem quer que seja". Disso pode ser entendido que é responsabilidade do médico fazer, segundo seu julgamento e habilidade, o que for possível no melhor interesse de seu paciente. Colocado dessa forma, esse dever hipocrático soa menos atraente, mas em termos de situação de vida real, a última coisa que se deve fazer é colocar peso à miséria, angústia e incerteza. Dessa forma, e assim colocado, nos parece, então, mais plausível, mas não necessariamente certo ou correto do ponto de vista ético ${ }^{12}$. O que deveria sempre ser ponderado é o juízo entre a utilização dos meios terapêuticos tecnológicos e os benefícios que eles podem trazer aos doentes, evitando-se seu uso indiscriminado pelo fato de, simplesmente, existirem ou estarem disponíveis.

Observamos que, mesmo sendo de comprovação difícil, pode haver maior conflito de interesses quando se analisa o lado empresarial dos hospitais. A eles, sim, interessa a permanência desses pacientes em seus leitos de UTI e a utilização da gama de recursos que promove a manutenção da vida. Mas também é verdade que essa ingerência, no dia a dia da terapia intensiva, não é notada e, mais uma vez, o tema se restringe aos próprios profissionais da saúde que aí exercem suas atividades.

Quanto menos discutimos a terminalidade e a prática médica em leitos hospitalares frente ao fim da vida imposto aos pacientes gravemente enfermos, mais isso é discutido em outros âmbitos. Em 1995, Geoffrey Gorer, um sociólogo inglês, publicou "A Pornografia da Morte". Nesse trabalho, o autor enfatiza que os temas luto, morte e morrer estão banidos e proscritos da sociedade atual. Ele relata que no início do século XIX todos, incluindo crianças, estavam familiarizados com a morte. Os nascimentos, no entanto, assim como as relações sexuais eram considerados pornográficos. Os costumes se inverteram: as atividades reprodutivas passaram a ser assunto comum, debatido sem constrangimentos e a morte e o morrer foram banidos das conversações ${ }^{13}$.

Da mesma forma, em maio de 1991, o jornal The Washington Post publicou $\mathrm{O}$ artigo assinado pelo médico John $\mathrm{H}$. Flashen intitulado "Escolhendo morte ou mamba na UTI" no qual, em história de ficção, três missionários religiosos estavam aprisionados por canibais e o chefe tribal oferecia duas opções: morte ou mamba. Dois deles, sem saber o significado de mamba a escolheram na suposição que seria melhor que a morte, a qual bem conheciam. Souberam, então, que mamba era uma cobra venenosa cuja picada impunha enorme e insuportável sofrimento antes de culminar, após algumas horas, em morte. Viveram, assim, uma longa agonia antes do final. Após presenciar o insólito sofrimento dos companheiros, o terceiro missionário rogou ao chefe canibal que Ihe concedesse a morte. Recebeu como resposta que a teria sem dúvida, porém, precedida de um pouquinho de mamba. A questão apresentada pelo autor aos médicos é sobre a quantidade de mamba imposta diariamente a inúmeros pacientes internados em UTIs ${ }^{14}$.

As escolas médicas, em sua grande maioria, ainda não abordam a terminalidade em sua matriz curricular e nem incitam os seus alunos a essa discussão. Se isso fosse feito, talvez contribuísse para o amadurecimento dos diversos pontos que compõem o mosaico dessa, nem sempre duvidosa, mas sempre conflituosa situação a ser definida.

As comissões de bioética (ética da vida) acenam como um alentador instrumento de discussão e estudo de questões contemporâneas polêmicas. Assim, são discutidos temas como a reprodução humana medicamente assistida, engenharia genética, clonagem, eutanásia, abortamento, terminalidade da vida e distanásia. Nitidamente há avanço nos centros hospitalares que dispõem dessas comissões e muito se tem crescido nesse sentido, o que já é facilmente percebido no Conselho Regional de Medicina de São Paulo e no Conselho Federal.

Por outro lado, e de maneira interessante, a bioética provoca dois sentimentos contraditórios nas pessoas: o fascínio e a repulsa. O primeiro, pela ilusão de ter encontrado o mecanismo legítimo de mediação para os conflitos morais. O segundo, pela própria falência do projeto bioético de se tornar a resposta definitiva a esses conflitos $^{17}$. Isso se torna ainda mais evidente quando a morte passa a assunto principal, não encarado como um desfecho natural do processo de vida e das condições 
Hilkner M, Hilkner RR. A questão da terminalidade.

clínicas inexoravelmente terminais.

Bioética é um neologismo ao qual se relaciona tudo que disser respeito à vida e, decorre daí, a dificuldade de uma definição sumária. Tratase de um novo estudo, de uma nova reflexão e perfil de pesquisa, fruto de uma sociedade que atingiu a democracia e está em pleno exercício da cidadania $^{4,18,19}$. De certa forma, a Bioética engloba a Deontologia Médica (do grego deon que significa obrigação, dever), que tem foco maior nas regras e obrigações do que nas consequências, mas não define essas obrigações e nem mesmo esclarece o que deve ser feito em situações de conflito de obrigações $^{5}$. O termo bioética foi cunhado pela primeira vez pelo oncologista norte americano Van Rensselaer Potter em 1970 e tenta interligar diferentes áreas do conhecimento. Assim, oficinas frequentes, câmaras de discussão e aprendizado, exercício da tolerância e convivência com a pluralidade são caminhos a serem enfrentados para que se contorne a heterogeneidade de opiniões e princípios quando nos deparamos com os dilemas impostos pelo fim da vida nos leito de uma Terapia Intensiva. Essa missão pode ser desempenhada pelo exercício da Bioética nos hospitais.

Obviamente, a nossa própria não aceitação da finitude da vida se manifesta em leitos hospitalares quando uma ou mais doenças nos conduzem inexoravelmente ao processo da morte. Esse sentimento surge tanto nos médicos quanto nos familiares e amigos e, todos juntos, dentro de uma grande heterogeneidade de conceitos, razões, conflitos, crenças e esperanças têm que buscar a melhor abordagem desse tema pelo diálogo franco, aberto, caridoso e honesto, exatamente durante a internação ou até mesmo antes da manifestação maior da gravidade de uma doença previamente diagnosticada. Ou seja, entendemos que há a necessidade de, dentro das possibilidades, conversar mais abertamente sobre o que pode vir a ocorrer no curso natural de uma doença e o que poderá ou deverá ser feito em relação a isso. As pessoas reagem distintamente a situações adversas e, naturalmente, as condições intelectuais e emocionais de cada pessoa envolvida devem ser levadas em consideração e analisadas sempre. Mas, de uma maneira geral, a discussão sobre a terminalidade deve começar até mesmo fora dos leitos hospitalares, estendendo-se aos serviços de assistência em domicílio, de cuidados paliativos, aos asilos, ao cuidado de pacientes cronicamente e há longo tempo irreversivelmente acamados ainda em suas residências. Da mesma maneira, os profissionais que exercem suas atividades nos leitos de clínica médica poderiam, cada vez mais, trabalhar o tema perante os mesmos quadros sempre que houver piora clínica de um paciente sabidamente terminal e evitar, assim, mais uma internação prolongada, desnecessária, cara e sofrida em ambiente de terapia intensiva.

O novo Código de Ética Médica, aprovado pela resolução do Conselho Federal de Medicina (CFM) 1.931/2009 inovou ao abordar, pela primeira vez, o tema terminalidade da vida, tratada em dois dispositivos. No Capítulo I (Princípios Fundamentais): "Nas situações clínicas irreversíveis e terminais, o médico evitará a realização de procedimentos diagnósticos e terapêuticos desnecessários e propiciará aos pacientes sob sua atenção todos os cuidados paliativos apropriados" ${ }^{21}$. No Capítulo V, Art. 41 (Relação com Pacientes e Familiares) é vedado ao médico: "Abreviar a vida do paciente, ainda que a pedido deste ou de seu representante legal. Parágrafo único: Nos caos de doença incurável e terminal, deve o médico oferecer todos os cuidados paliativos disponíveis sem empreender ações diagnósticas ou terapêuticas inúteis ou obstinadas, levando sempre em consideração a vontade expressa do paciente ou, na sua impossibilidade, a de seu representante legal"21. Isso posto, reforça-se a idéia de que cuidados paliativos em casos terminais não é eutanásia ${ }^{4,20}$ e nem abandono e, sim, um uso mais racional das ações médicas nesse exato momento da vida.

Ainda nesse sentido, o CFM, observando a inexistência de regulamentação sobre diretivas antecipadas de vontade do paciente no contexto da ética médica brasileira e considerando, também, a necessidade de disciplinar a conduta do médico em face das mesmas porque, na prática, os médicos podem se defrontar com essa situação de ordem ética, publicou em 31 de agosto de 2012, a Resolução 1.995/2012 na qual resolve ${ }^{22}$ :

Art. $1^{\circ}$ Definir diretivas antecipadas de vontade como o conjunto de desejos, prévia e expressamente manifestados pelo paciente, sobre cuidados e tratamentos que quer, ou não, receber no momento em que estiver incapacitado de expressar, livre e autonomamente, sua vontade.

Art. $2^{\circ}$ Nas decisões sobre cuidados e tratamentos de pacientes que se encontram incapazes de comunicar-se, ou de expressar de maneira livre e independente suas vontades, o médico levará em consideração suas diretivas antecipadas de vontade.

$\S 1^{\circ}$ Caso o paciente tenha designado um representante para tal fim, suas informações serão levadas em consideração pelo médico. 
\$ $2^{\circ} \mathrm{O}$ médico deixará de levar em consideração as diretivas antecipadas de vontade do paciente ou representante que, em sua análise, estiverem em desacordo com os preceitos ditados pelo Código de Ética Médica.

$\S 3^{\circ}$ As diretivas antecipadas do paciente prevalecerão sobre qualquer outro parecer não médico, inclusive sobre os desejos dos familiares.

$\S 4^{\circ} \mathrm{O}$ médico registrará, no prontuário, as diretivas antecipadas de vontade que Ihes foram diretamente comunicadas pelo paciente.

$\S 5^{\circ}$ Não sendo conhecidas as diretivas antecipadas de vontade do paciente, nem havendo representante designado, familiares disponíveis ou falta de consenso entre estes, o médico recorrerá ao Comitê de Bioética da instituição, caso exista, ou, na falta deste, à Comissão de Ética Médica do hospital ou ao Conselho Regional e Federal de Medicina para fundamentar sua decisão sobre conflitos éticos, quando entender esta medida necessária e conveniente.

Cabe aqui ressaltar, entre tantos comentários sobre a distanásia, o que fazer pelos pacientes nesse momento delicado de suas vidas. Pode-se ter a impressão que esses pacientes no estágio final de suas vidas não merecem ou não necessitem de maiores cuidados e isso, definitivamente, não procede. É importante sempre ter em mente que ninguém pode ficar sem tratamento de uma patologia aguda mesmo sendo portador de qualquer quadro crônico. Dessa forma, infecções devem ser tratadas, as dores sempre amenizadas, curativos realizados e escaras debridadas. Os cuidados com alimentação e hidratação devem sempre ser mantidos e os pacientes devem receber ainda maiores cuidados e atenção de toda equipe multidisciplinar que compõe a UTI. Isso se estende aos cuidados fisioterápicos, psicológicos e de enfermagem, além dos cuidados médicos. A tão preconizada humanização das terapias intensivas tem, nesse momento da vida dos pacientes gravemente enfermos, uma hora precisa para se fazer presente junto de seus familiares e do próprio enfermo, justamente pelo difícil momento de vida em que todos se encontram. Esse conjunto de atitudes e tratamento, atualmente compreendidos como cuidados paliativos ${ }^{20}$, em nada se relaciona com cuidados fúteis, desnecessários ou infrutíferos aos pacientes. Pelo contrário. Além disso, é digno de nota o empenho e a defesa de religiosos pela dignidade ao fim da vida ${ }^{2,3,12,18,23}$ e a atenção solidária religiosa no processo de morrer que, comumente, gera muita dor e sofrimento e, na maioria das vezes, apenas a fé e a espiritualidade podem proporcionar algum conforto ${ }^{23}$.

Condutas médicas consideradas técnica e eticamente adequadas - como não investir em determinados pacientes, não podem ser consideradas ilícitas desde que respeitem a dignidade da pessoa. Mesmo não havendo leis específicas sobre o tema da morte digna é possível a argumentação sobre o princípio constitucional do direito à vida com dignidade. Dessa forma, o médico que limita recursos terapêuticos aos pacientes em processo de morte irreversível, não está violando o ordenamento jurídico brasileiro. A Constituição Federal brasileira afirma ser a dignidade da pessoa um princípio fundamental do Estado Democrático de Direito ${ }^{10}$.

De qualquer forma, nos parece cada vez mais necessário o amadurecimento dessa discussão da vida finita e da terminalidade entre os próprios médicos, com a consequente formação de uma linguagem, se não única, mais homogênea, com a sociedade, maior racionalização de recursos e, definitivamente, maior treinamento no tema ainda nos bancos das faculdades de medicina.

Aqueles que tratam de pacientes no final da vida precisam entender a morte como inevitável, e não como uma derrota, e que a defesa da vida é uma luta incansável para que pessoas não vivam sem vida; e viver e morrer com dignidade é um direito de todos ${ }^{23}$

Hilkner M, Hilkner RR. The issue of terminally ill patients. Saúde, Ética \& Justiça. 2012;17(2):75-81.

ABSTRACT: The authors present the situation of terminally ill patients commonly admitted to Intensive Care Units and its complex relationship with doctors, relatives and society. They discuss the end of life in which there are conflicts of interest, professional conflicts and ethical and religious conflicts as well as those regarding resource allocation in healthcare.

KEYWORDS: Critical illness; Intensive care units; Ethics, medical; Bioethics; Hospice care.

\section{REFERÊNCIAS}

1. McPhee SJ, Papadakis MA, Rabow MW. Current

2011 medical diagnosis and treatment. 50a ed. New 
Hilkner M, Hilkner RR. A questão da terminalidade.

York: McGraw-Hill; 2011.

2. Pessini L. Distanásia: até quando prolongar a vida? São Paulo: Edições Loyola; 2001. p.143-62.

3. Pessini L. Eutanásia: por que abreviar a vida? São Paulo: Edições Loyola; 2004.

4. Pittelli SD, Oliveira RA. Eutanásia e sua relação com casos terminais, doenças incuráveis, estados neurovegetativos, estados sequelares graves ou de sofrimento intenso e irreversível e morte encefálica. Saúde Ética Justiça. 2009;14(1):32-9.

5. Johnston C, Bradbury P. 100 cases in clinical ethics and law. London: Hodder Arnold; 2008. p.7-8.

6. Civetta J. Estabelecendo objetivos: perspectivas do tratamento. In: Civetta JM, Taylor RW, Kirby RR. Tratado de terapia intensiva. São Paulo: Manole; 1992. v.1, p.5-13.

7. Gawryszewski VP, Pellini ACG, Hidalgo N, Valencich DMO, Brumini R O. Impacto dos acidentes e violências nos gastos da saúde. BEPA. 2006;40(3):553-5562 [citado 6 nov. 2012]. Disponível em: http://www.cve. saude.sp.gov.br/agencia/bepa27_violencia.htm.

8. Rubin SB. When doctors say no: the battleground of medical futility. Bloomington: Indiana University Press; 1998.

9. Yaguchi A, Truog RD, Curtis JR, Luce JM, Levy MM, Mélot C, Vincent J-L. International differences in endof-life attitudes in the intensive care unit: results of a survey. Arch Intern Med. 2005;165(17):1970-5.

10. Pithan LH. A dignidade humana como fundamento jurídico das "ordens de não-ressuscitação" hospitalares. Porto Alegre: EIPUCRS; 2004.

11 CREMESP - Conselho Regional de Medicina (São Paulo). Doente terminal, destino de pré-embriões, clonagem e meio ambiente. São Paulo: CREMESP; 2005.

12. Almeida M. Comentário sobre os princípios fundamentais da Bioética. Perspectiva médica. In: Pessini L, Barchifontaine CP. Fundamentos da bioética. São Paulo: Paulus; 1996. p.56-67.

13. Guerra MAT. Doente Terminal. In: CREMESP -
Conselho Regional de Medicina (São Paulo). Doente terminal, destino de pré-embriões, clonagem e meio ambiente. São Paulo: CREMESP; 2005. p.19-20.

14 Siqueira JE. Doente Terminal. A morte ou mamba na UTI. In: CREMESP - Conselho Regional de Medicina (São Paulo). Doente terminal, destino de préembriões, clonagem e meio ambiente. São Paulo: CREMESP; 2005. p.18-9.

15. CREMESP - Conselho Regional de Medicina (São Paulo). Entrevistas exclusivas com grandes nomes da bioética (estrangeiros). São Paulo: CREMESP; 2009.

16. Câmara Técnica sobre a Terminalidade da Vida e Cuidados Paliativos. In: CFM - Conselho Federal de Medicina. Conflitos bioéticos do viver e do morrer. Brasília: CFM; 2011.

17. Diniz D, Guilhem D. O que é bioética. São Paulo: Brasiliense; 2002.

18. Correia FA. Alguns desafios atuais da bioética. In: Pessini L, Barchifontaine CP. Fundamentos da bioética. 3a ed. São Paulo: Paulus; 2005. p.30-50.

19. Muñoz DR. Bioética: o novo caminho da ética em saúde. Saúde Ética Justiça. 2003;8(1/2):1-6.

20. Melo AGC, Caponero R. Cuidados paliativos abordagem contínua e integral. In: Santos FS. Cuidados paliativos: discutindo a vida, a morte e o morrer. São Paulo: Atheneu; 2009. p.257-67.

21. Brasil. Conselho Federal de Medicina - CFM. Código de ética médica [citado 31 out. 2012]. Disponível em: http://portal.cfm.org.br/index.php?option=com_conte nt\&view=category\&id=9\&/temid=122

22. Brasil. Conselho Federal de Medicina - CFM. Resolução CFM nำ1.995/2012. Dispõe sobre as diretivas antecipadas de vontades dos pacientes. D.O.U., 31 ago. 2012, Seção I: 269-270 [citado 31 out. 2012]. Disponível em: http://www.portalmedico. org.br/resolucoes/CFM/2012/1995_2012.pdf

23. Martins AA. Pastoral da Saúde em defesa da vida e do morrer com dignidade: fundamentos e prática. São Paulo: Centro Universitário São Camilo; 2010. 